\title{
ESTIMATION OF STATURE FROM HAND AND FOOT DIMENSIONS IN HAUSA NEONATES: A HOSPITAL-BASED STUDY
}

\author{
${ }^{1}$ Modibbo, M. H., ${ }^{1}$ Taura, M. G., ${ }^{2}$ Agu, O. C. and ${ }^{3}$ Bashir, U. \\ ${ }^{1}$ Department of Anatomy, Faculty of Medicine, Bayero University, Kano, Nigeria \\ 2Department of Obsterics \& Gynaecology, Murtala Muhammad Specialist Hospital, Kano, Nigeria \\ ${ }^{3}$ Department of Community Medicine, Bayero University, Kano, Nigeria \\ *Correspondence author: drmodibbo@ymail.com
}

\begin{abstract}
Stature (body height) is an important and useful anthropometric parameter for identification of an individual. The aim of the study is to find the correlation between Stature (Length) and measurements from hand and foot dimensions (Hand Length, Hand Breadth, Foot Length and Foot Breadth). 501 randomly selected Hausa neonates (zero to 28 days) were measured for each of the parameters. All the parameters showed to correlate with Stature at $p<0.01$. Foot Length showed the highest correlation value of 0.75 , while Foot Breadth had the least correlation value of 0.43 . Hand Breadth and Hand Length also had correlation values of 0.62 and 0.60 respectively. Multiple linear regression equations were formed for each of the parameters. In conclusion, the study has provided regression equations that can be used to estimate stature in Hausa neonates of Kano State origin.
\end{abstract}

Key words: Stature, Hausa neonates, Hand and Foot dimensions.

\section{INTRODUCTION}

Stature (or height) of an individual is useful information for making forensic identifications. In neonates, 'Stature' means length. Estimation of stature has been considered as one of the parameters of forensic anthropology and will assist in establishing the biological profile of a person (Krishan and Sharma 2007). Anthropometry provides the single most portable, universally applicable, inexpensive and noninvasive technique for assessing the size, proportion and composition of the human body. It reflects both health and nutritional status and predicts performance, health and survival. As such it is a valuable, but currently underused tool for guiding public health policies and clinical decisions (Ferro et al., 1993). Stature estimation from foot dimensions can be used in developing descriptions of suspects from evidences given by witnesses at the scene of crime (Giles and Vallandigham, 1991; Gordon and Buikstra, 1992). 'Stature' is one of the most important elements in the identification of an individual. Before estimating stature, one must determine the race, sex, and age of the individual as stature varies with these variables. Potential stature refers to the stature of an individual who has not undergone skeletal changes associated with the aging process. These changes do not occur in most people who are 30 years of age or less at the time of death (John et al., 1990). Living stature refers to the stature of an individual who has undergone degenerative changes associated with the aging process which results in a decrease in stature. Most people who are 30 years old or older at the time of death have undergone some of these changes (John et al., 1990). Regression analysis is one of the most heavily used statistical methods in physical anthropology. This is largely as a result of its ubiquity and wide availability in statistical packages. Although approximate stature of an individual can be estimated from most of the long bones using either multiplication factors or regression formulae, studies on estimation of stature in neonates are limited.

\section{MATERIALS AND METHODS}

\section{Materials}

Tools used for the study include: - Sliding vernier caliper, plastic measuring tape and infant measuring mat.

\section{Methods}

The study is a cross-sectional one, 501 neonates (271 males and 230 females) born to Hausa parents of Kano State origin, were selected randomly. Grand parentage criteria were used in selecting those neonates from Hausa origin. Ethical clearance was obtained from the ethical committee of Kano State Health Management Board, through Murtala Muhammad Specialist Hospital, Kano. The procedure, aims and objectives of the study were explained to the mothers of the participants. And their informed consent obtained. Data were collected over a period of six weeks (April - May 2012).

The neonates were measured for the following parameters (according to standard measurement techniques), using the left side of the body (Martin and Sallar, 1959; Allbrook 1961):

Stature (ST) in cm: Measured as the projective distance between the highest point on the head (vertex), and the most posterior projecting point of the heel, using infant measuring mat in supine position.

Hand length $(\mathrm{HL})$ in $\mathrm{cm}$ : Measured from the midpoint of the distal wrist crease, to the tip of the middle finger using a plastic measuring tape (palmer surface of the hand in supine position). 
Hand breadth (HB) in $\mathrm{cm}$ : Measured from the head of the $5^{\text {th }}$ to $2^{\text {nd }}$ metacarpal using a sliding vernier caliper (palmer surface of the hand in supine position).

Foot length (FL) in $\mathrm{cm}$ : Measured as a straight distance between the most posterior projecting point of the heel and anterior projecting point (the end of 1st or 2 nd toe) using a plastic measuring tape (Planter view of the sole of the foot in supine position).

Foot breadth (FB) in $\mathrm{cm}$ : Measured at the widest point of the sole, which is from the metatarsophalangeal joint of the $1^{\text {st }}$ metatarsal and that of the $5^{\text {th }}$ metatarsal of the foot using a sliding vernier caliper. (Planter view of the sole of the foot in supine position).

\section{Data analysis}

Data analyses were carried out using Minitab 16.0 statistical software. The data were expressed as Mean \pm Standard Deviation (S.D). $P<0.05$ was considered statistically significant. Pearson's correlation analysis was used in relating the variables with one another. Microsoft Office Word 2007 was used for the tables. Linear regression equations for estimation of Stature were formed for each of the measured parameter as: $y=a+b x$, where $y=$ Stature (Dependent variable), $a=$ Constant, $b=$ Regression coefficient of the independent variable and $x=$ Measured parameters (Independent variables).

\section{RESULTS \\ Descriptive statistics}

Table 1 presents the mean values \pm standard deviations (S.D), and ranges for the measured parameters. The subjects had mean stature (ST) of $49.17 \mathrm{~cm} \pm 3.10$ S.D, the minimum value was 40.00 $\mathrm{cm}$, while the maximum value was $56.00 \mathrm{~cm}$. The mean value for Hand Length was found to be $6.82 \mathrm{~cm}$ \pm 0.46 S.D, with minimum value of 5.20 and a maximum value of 8.10 . Hand Breadth had a mean value of $3.32 \pm 0.31$ S.D, and a minimum value of 2.50, and a maximum value of 4.30 . Mean value for Foot Length (FL) was $8.15 \mathrm{~cm} \pm 0.58$ S.D, the minimum value was $6.30 \mathrm{~cm}$, while the maximum value was $9.50 \mathrm{~cm}$. Foot Breadth (FB) had mean value of $3.07 \mathrm{~cm} \pm 0.29$ S.D, the minimum and maximum values were $2.20 \mathrm{~cm}$ and $4.00 \mathrm{~cm}$ respectively.

Table 1: Descriptive statistics of the measured parameters $(\mathrm{cm})$ among Hausa neonates

S.No. Measured parameter $\quad$ Mean \pm S.D. $\quad$ Minimum $\quad$ Maximum

\begin{tabular}{llccr}
\hline 1. & STATURE & $49.17 \pm 3.10$ & 40.00 & 56.00 \\
2. & HAND LENGTH & $6.82 \pm 0.46$ & 5.20 & 8.10 \\
3. & HAND BREADTH & $3.32 \pm 0.31$ & 2.50 & 4.30 \\
4. & FOOT LENGTH & $8.15 \pm 0.58$ & 6.30 & 9.50 \\
$\mathbf{5 .}$ & FOOT BREADTH & $3.07 \pm 0.29$ & 2.20 & 4.00 \\
\hline
\end{tabular}

$(n=501)$

Among the four measured parameters from the hand and foot dimensions, foot length exhibits the highest value of standard deviation (0.58), while the lowest value was observed for foot breadth (0.29).

\section{Correlation between the measured parameters}

Tables 2 shows the correlation between Stature and the measured parameters among the Hausa neonates $(n=501)$. Stature was found to be correlated with the measured parameters, and has been observed to correlate significantly with Foot Length $(r=0.75, P<$ 0.01). The coefficients of correlation are also statistically significant $(p<0.01)$ between stature and Hand Breadth $(r=0.62)$ and stature with Hand Length $(r=0.60)$. A positive correlation was also observed between stature and Foot Breadth $(r=0.43$, $p<0.01)$.

Table 2: Coefficient of correlation ( $r$ ) values of the measured parameters (cm) among Hausa neonates

\begin{tabular}{lllr}
\hline S.No. & Measured parameters & $\boldsymbol{r}$ & Level of significance \\
\hline $\mathbf{1 .}$ & FOOT LENGTH & 0.75 & $P<0.01$ \\
$\mathbf{2 .}$ & HAND BREADTH & 0.62 & $P<0.01$ \\
$\mathbf{3 .}$ & HAND LENGTH & 0.60 & $P<0.01$ \\
$\mathbf{4 .}$ & FOOT BREADTH & 0.43 & $P<0.01$ \\
\hline $\mathbf{n = 5 0 1 )}$ & & &
\end{tabular}

\section{Multiple linear regression equations}

Table 3 presents the linear regression equations for the estimation of stature in Hausa neonates of Kano State-Nigeria, using four parameters from hand and foot dimensions (Hand Length, Hand Breadth, Foot Length and Foot Breadth). Foot Length (FL) was found to provide the best estimate of stature, as it exhibits the overall highest correlation $(r)$ value of 0.75 and had the least value of standard error of estimate (S.E.E.) of \pm 2.06 . Hand breadth (HB), provides the second best estimate of stature $(r=$ 0.62 , S E E $= \pm 2.4$ ). The $r$ and S.E.E. values for Hand Length $(\mathrm{HL})$ were 0.60 , and \pm 2.47 respectively. 
Foot Breadth (FB) which exhibits the highest S.E.E. value ( \pm 2.84 ) and the lowest $r$ value of 0.43 , should be used only in the absence of the other parameters from the hand and foot dimensions. Figures 1 to 4 shows the regression best line of fits for the various equations.

Table 3: Linear regression equations for stature $(\mathrm{cm})$ estimation from the measured parameters (cm) among Hausa neonates

\begin{tabular}{llcccc}
\hline S.No. & $\begin{array}{l}\text { Measured } \\
\text { parameters }\end{array}$ & $\boldsymbol{b}$ & Linear regression equations & $\boldsymbol{r}$ & S.E.E. \\
\hline 1. & FOOT LENGTH & 3.99 & ST $=16.7+3.99(F L)$ & 0.75 & \pm 2.06 \\
2. & HAND BREADTH & 6.25 & ST $=28.4+6.25(H B)$ & 0.62 & \pm 2.42 \\
3. & HAND LENGTH & 4.11 & ST $=21.2+4.11(H L)$ & 0.60 & \pm 2.47 \\
4. & FOOT BREADTH & 4.65 & ST $=34.9+4.65(F B)$ & 0.43 & \pm 2.80 \\
\hline
\end{tabular}

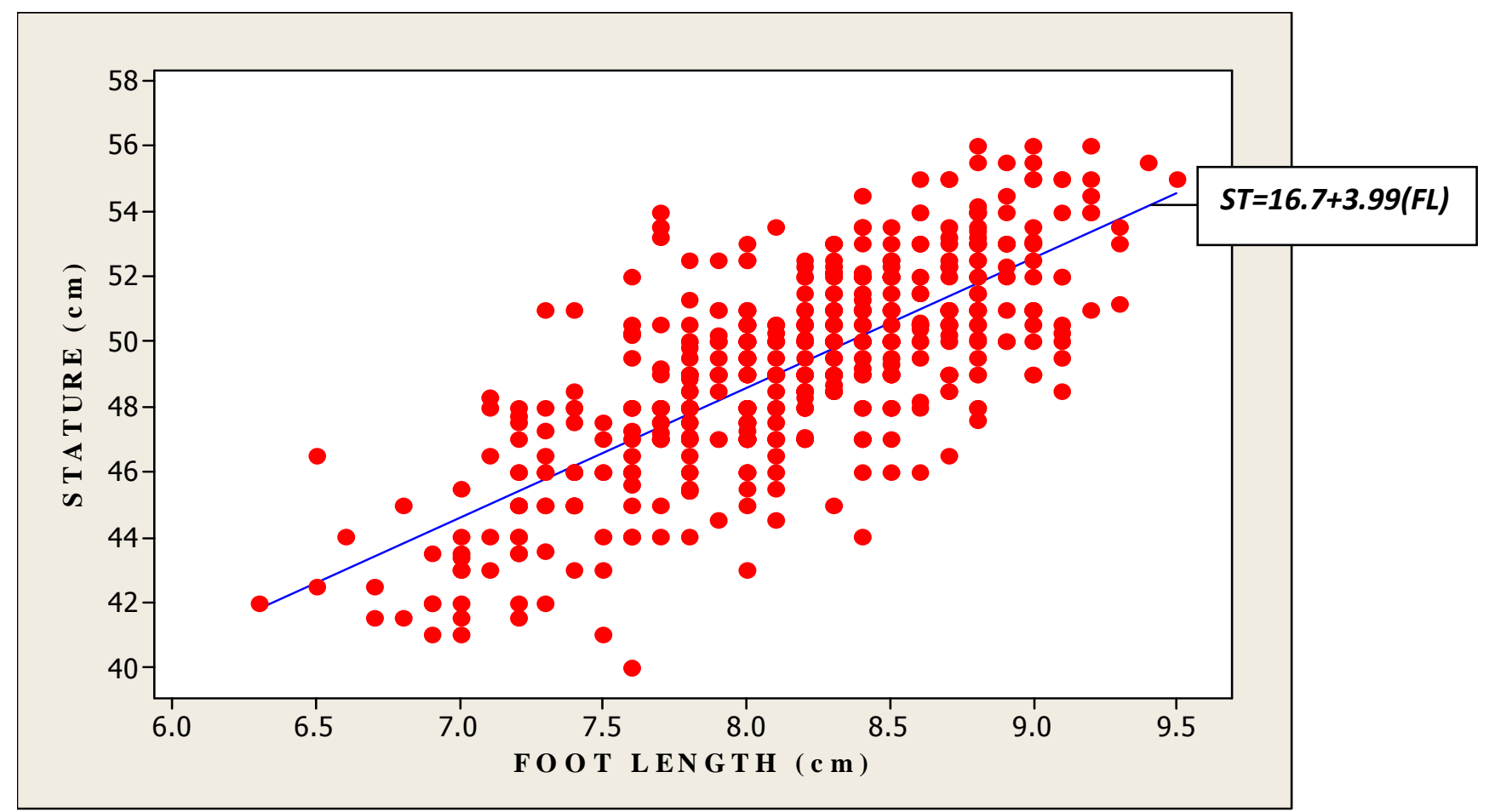

Fig. 1: Regression Line of Stature on Foot Length

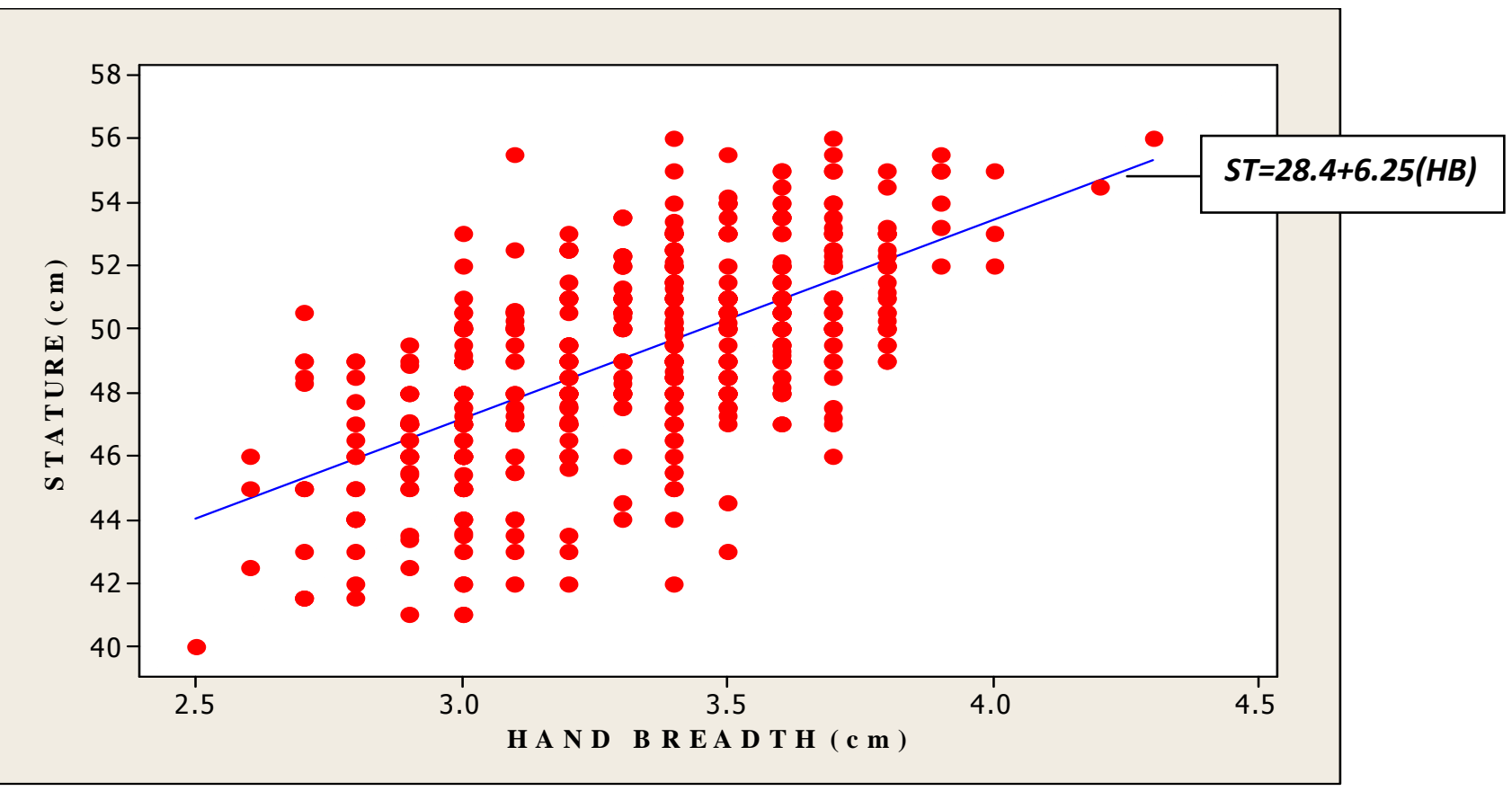

Fig. 2: Regression Line of Stature on Hand Breadth 


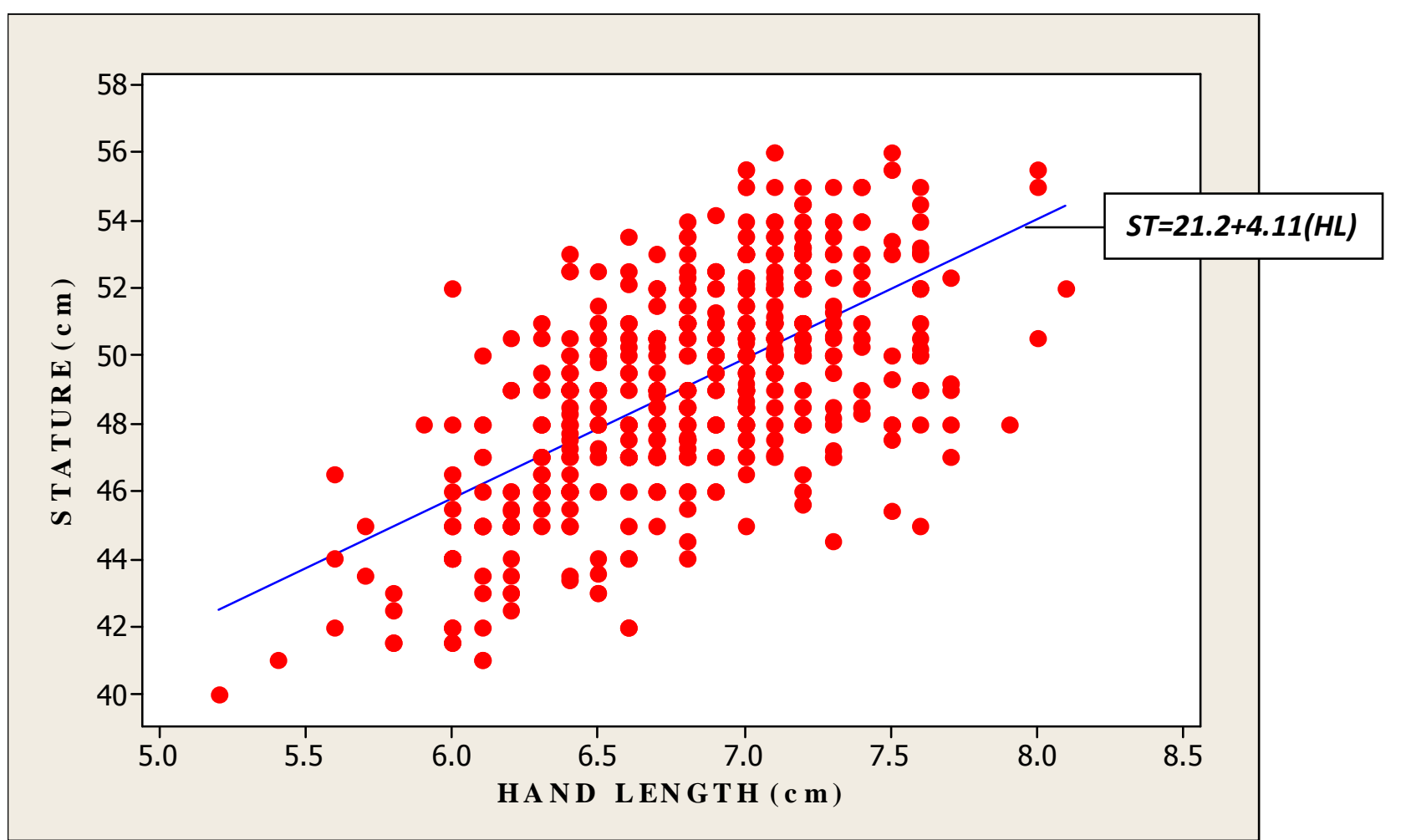

Fig. 3: Regression Line of Stature on Hand Length

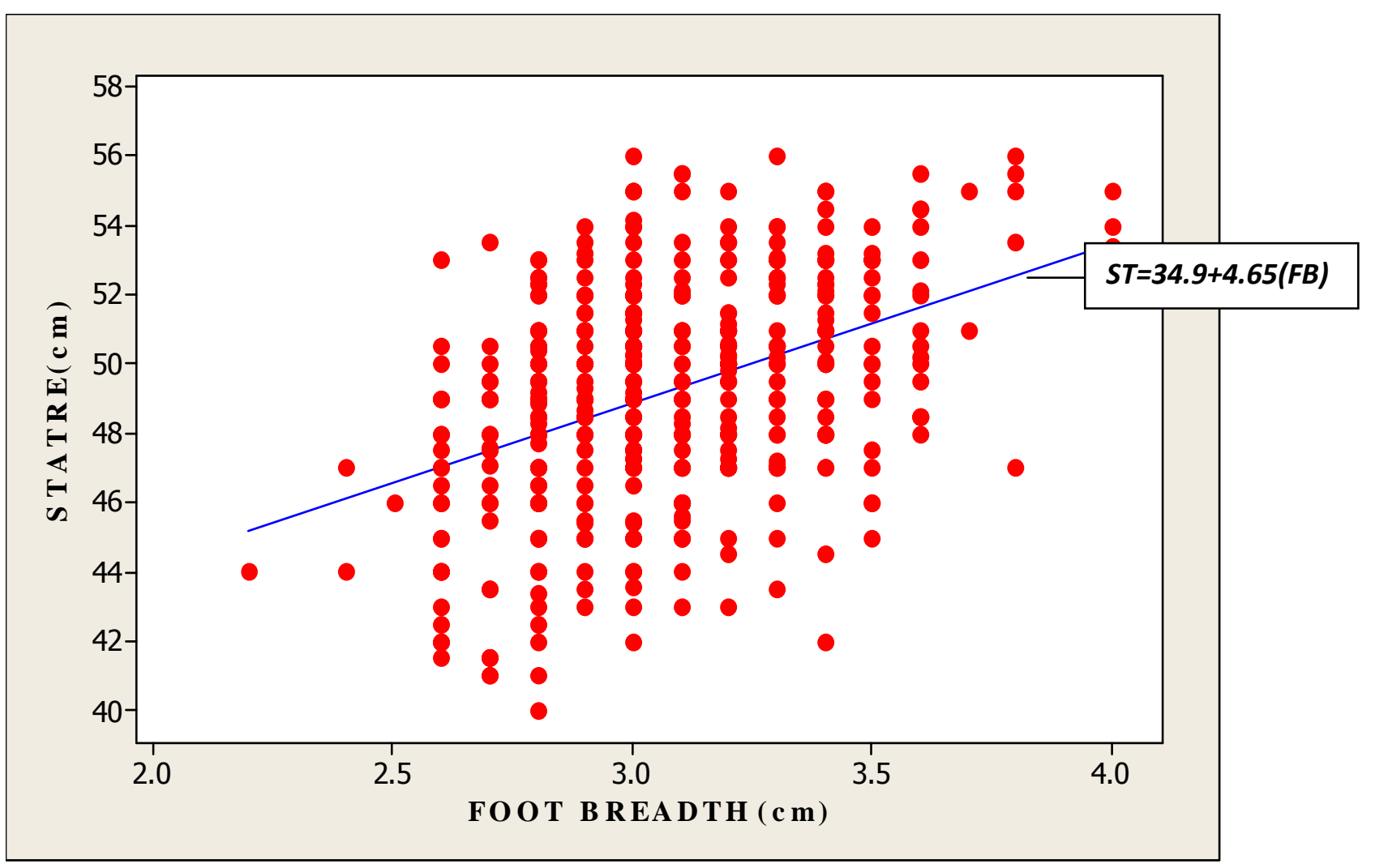

Fig. 4: Regression Line of Stature on Foot Breadth 


\section{DISCUSSION}

The objective of the study is to find the relationship (correlation) between Statures (length in neonates) and the measured parameters from hand and foot dimensions. It also aimed at forming multiple linear regression equations for estimating stature among Hausa neonates of Kano State origin. Foot Length was found to have the highest correlation value of 0.75 , while foot breadth had least correlation value of 0.43 . These values were similar to those obtained by Krishnan and Sharma (2007) in a study they conducted to examine the relationship between stature and dimensions of hands and feet among Raj puts of Himachal Pradesh - a North Indian endogamous population. Hand length, hand breadth, foot length and foot breadth of 246 subjects were considered and found that, among the upper limb parameters, hand breadth was found to be the best estimate of stature, while among the lower limb parameters, foot-length was the best measure of estimating stature of an individual. The best overall estimate was found to be from the foot length. In the present study, among the measured parameters from the hand and foot measurements, hand breadth was also found to be the best estimate of stature among the upper limb parameters $(r=0.62)$, and footlength ( $r=0.75$ ) was also found to be the best estimate of stature among the lower limb parameter. Foot length had the highest overall $\square r \square$ value. Therefore stature can be reliably estimated in Hausa neonates using Foot Length because it correlated significantly with stature $(0.75, p<0.01)$. Kanchan et al., (2008) had similar conclusions also to the present study. Sen and Ghosch (2008) conducted a study on estimation of stature from foot length and foot

\section{REFERENCES}

Allbrook, D. (1961): The estimation of stature in British and East African males based on tibial and ulna bone lengths. Journal of Forensic Medicine, 8: 15-28.

Bhavna, and Nath, S. (2009): Use of Lower Limb Measurements in Reconstructing Stature among Shia Muslims. Internet Journal of Biological Anthropology, 2(2): $86-87$.

Ferro, L.A., Hass, J. and Ransome Kuti, O. (1993): WHO expert committee on physical status: The use and interpretation of Anthropometry. Geneva 1-34.

Giles, E. and Vallandigham, P.H. (1991): Height Estimation from Foot and Shoeprint Length. Journal of Forensic Science, 36: 1134-1151.

Gordon, C.C. and Buikstra, J.E. (1992): Linear Models for the Prediction of Stature from Foot and Boot Dimensions. Journal of Forensic Science, 37: 771-782.

John, D.S., Denis, C.M. and Reubin, A. (1990): Longitudinal change in height of Men and breadth among the Rajbanshi: An indigenous population of North Bengal. It was shown that among the lower limb parameters, foot length had the highest correlation value with stature among the 350 adult Rajbanshi and 100 adult Meche individuals aged 18 - 50 year, while foot breadth had the least correlation value. This implies that foot length is the best estimate of stature among the measured parameters; these findings were in agreement with the present study. Furthermore, Patel and Shah (2007), conducted a study based on the measurements of foot length and body height (stature) among 502 students between the ages of 17 to 22 years, they found that foot-length showed the highest degree of correlation with height of an individual. The present study also highlights a strong correlation between Stature and foot-length.

\section{CONCLUSION}

The study observed a significant correlation between Stature (Length) and the four measured parameters, with Foot Length having the highest correlation value, while Foot Breadth had the least correlation value. This shows that Foot Length will give a better estimate of Stature. Multiple linear regression equations were formed which can be used to estimate stature. Therefore, this study will help in establishing identity in neonates of Kano State origin.

\section{Acknowledgement}

The authors are very grateful to the management of Murtala Muhammad Specialist Hospital, Kano, for their understanding and support shown to us during the data collection. Our appreciation also goes to the participants and their parents.

Women. American journal of Epidemiology, Volume 150, No 9.

Kanchan, T., Menezes, R.G., Moudgil, R., Kaur, R., Kotian, M.S. and Garg, R.K. (2008): Stature Estimation from Foot Dimension. Forensic Science International, 179: 241.

Krishnan, K. and Sharma, A. (2007): Estimation of Stature from Dimensions of Hands and Feet in a North Indian Population. Journal of Forensic and Legal Medicine, 14(6): 327 332.

Martin, R. and Sallar, K. (1959): Lehrbuch der Anthropologie in systematischer. Fischer Darstellung, Stuttgart.

Patel, S. and Shah, M. (2007): Estimation of height from measurements of foot length in Gujarat region. Journal of Anatomical Society of India, 56 (1): $25-27$.

Sen, J. and Ghosch, S. (2008): Estimation of stature from foot length and foot breadth among the Rajbanshi: an indigenous population of North Bengal. Forensic Science International, 181 (1): 55 . 